\title{
Cómo mueren las democracias, de Steven Levitsky y Daniel Ziblatt (2018), Ariel, 336 pp.
}

DOI: 10.17230/co-herencia.18.35.14

\section{Jorge Brower Beltramin*}

jorge.brower@usach.cl

El comienzo del siglo Xxi ha encontrado a los investigadores del área de las ciencias políticas muy preocupados por el estado en el que se halla la democracia, representada en las instituciones que la ponen en marcha en diversas regiones del mundo. El análisis y las conclusiones obtenidas dan cuenta de una crisis profunda con respecto a este sistema/tipo de gobierno. La crisis se expresa en falta de interés político, disminución Universidad de Santiago de Chile. Facultad Tecnológica, Departamento de Publicidad e Imagen. ORCID: $0000-0002-6968$ 2949 del apoyo a estos gobiernos y, sobre todo, pérdida de la confianza en la democracia y los actores políticos que le dan vida. Hace solo tres años, The Economist Intelligence Unit (2018) y Freedom in the World (2018) presentaron sendos estudios en los que la democracia aparece muy deteriorada como sistema de gobierno, en términos de credibilidad, cuestión muy delicada si pensamos en que son los ciudadanos los que acuden a las urnas, pero también piden niveles de participación horizontal cada vez de mayor protagonismo.

En este escenario, Levitsky y Ziblatt ponen el foco de atención en las nuevas formas de destrucción de la democracia. En el libro que nos ocupa, se ilustran de manera abundante y significativa estas nuevas formas que fracturan y debilitan a estos sistemas de gobierno. Cómo 
mueren las democracias combina de manera notable el aporte de una base teórica sólida con el análisis de casos en países que muestran el desmoronamiento de un sistema político en el pasado reciente. Lo que sucede, desde la perspectiva de estos académicos de Harvard, es que se ha colado en la estructura de los gobiernos denominados democráticos una nueva casta de políticos y líderes de distintos ámbitos del desarrollo social, que utilizan los instrumentos propios del sistema para ejercer el poder de manera autocrática, en ocasiones muy próxima a la instalación de totalitarismos tan dogmáticos como los de las anquilosadas ideologías concebidas en el siglo XIX.

De esta forma, en el marco filosófico y jurídico/normativo que proporciona el sistema de gobierno democrático, líderes de distantes latitudes ejercen liderazgos autoritarios que destruyen incluso las formas más simples de participación y autorregulación. Ya no son los golpes de estado de origen militar o cívico-militar los que atentan contra el desarrollo participativo y representativo de las sociedades, como se constató durante varias décadas del siglo xx. Efectivamente, estos golpes cruentos, que costaron la vida de miles de hombres y mujeres, fueron reemplazados en nuestros días por el advenimiento de sujetos autócratas que ejercen el poder, transgrediendo instancias participativas vitales para el ejercicio de la democracia.

Levitsky y Ziblatt nos ofrecen en este pedagógico texto un conjunto de indicadores que dan cuenta del comportamiento autoritario, los cuales sirven, por un lado, para identificar esta nueva modalidad de autoritarismo y, por otro, para corregir dicho comportamiento, en beneficio de la vida ciudadana democrática. Utilizando como referente el trabajo de Linz (La quiebra de las democracias, 1978), junto a los casos estudiados, los politólogos de Harvard entregan una matriz que contiene cuatro indicadores fundamentales del comportamiento político autoritario. Estos son el rechazo o aceptación a medias de las reglas del juego democrático; la negación de la legitimidad de los oponentes políticos; la intolerancia, con la consiguiente validación de la violencia y, por último, la predisposición a restringir las libertades civiles de la oposición, incluyendo todo medio de expresión pública (periódicos, radio, televisión, etcétera). 
A partir de la propuesta de estos indicadores, Levitsky y Ziblatt advierten que no solo los outsiders ingresan a la política en forma autocrática, inspirados en una verdad desarrollista que les ha sido entregada de manera muy personal. Los actores autoritarios en la política también provienen del propio sistema político establecido y ya normado. Unos y otros muestran su faceta más antisistémica cuando se empoderan y son validados ingenuamente por la ciudadanía.

En este ascenso al poder, Cómo mueren las democracias les asigna una responsabilidad decisiva a los partidos políticos. Son estos conglomerados los que deben resguardar el llamado "orden democrático", evitando la llegada al poder de figuras autoritarias. Los políticos deben ser, en consecuencia, guardianes de la democracia y los partidos no debieran sucumbir ante el carisma o populismo de aquellos personajes que asaltan el poder.

Sin duda, la preocupación de los autores gira en torno a la preservación de la democracia entendida como el mejor sistema de gobierno. Insisten en la necesidad de dos principios fundamentales para que goce de buena salud: la tolerancia y la contención. Ambas deben ser garantizadas por las instituciones en las que se sostiene este sistema político.

Finalmente, el análisis expuesto por los autores conduce al lector hacia reflexiones sobre los gobiernos actuales en cualquier parte del mundo y las consecuentes formas de gobernanza con las que se expresan dichos gobiernos. La advertencia central de Cómo mueren las democracias se focaliza en los líderes políticos que asumen el poder de manera autocrática, transgrediendo, desde una simulación consultiva amplia e inclusiva, las bases de una sociedad tolerante, que pueda expresarse con libertad y que, en instancias decisivas de los procesos de desarrollo, tenga la posibilidad de ser protagonista en la construcción de un futuro más equitativo y justo para todas y todos los ciudadanos $\mathbf{I}$ 


\section{Referencias}

Freedom House. (2018). Freedom in the World. https://freedomhouse.org/ sites/default/files/2020-02/FH_FIW_Report_2018_Final.pdf

Levitsky, S. y Ziblatt, D. (2018). Cómo mueren las democracias. Ariel.

Linz, J. (1978). La quiebra de las democracias. Alianza.

The Economist Intelligence Unit Limited (C). (2018). 